\title{
NUMERICAL RANGES ENCIRCLED BY ANALYTIC CURVES
}

\author{
BRIAN LINS
}

Abstract. Let $D$ be a bounded convex domain in $\mathbb{C}$ with a regular analytic boundary. Suppose that the numerical range $W(A)$ of a bounded linear operator $A$ is contained in $\bar{D}$. If $\overline{W(A)}$ intersects the boundary $\partial D$ at infinitely many points while the essential numerical range $W_{\text {ess }}(A)$ does not intersect $\partial D$, then $W(A)=\bar{D}$. This generalizes some infinite dimensional analogues of a result of Anderson [2, 4].

Mathematics subject classification (2010): Primary 47A12.

Keywords and phrases: Numerical range, essential numerical range.

\section{REFERENCES}

[1] S. K. BeRBERIAN, The numerical range of a normal operator, Duke Math. J., 31 (3): 479-483, 1964.

[2] R. Birbonshi, I. M. Spitkovsky, And P. D. SRivastava, A note on Anderson's theorem in the infinite-dimensional setting, J. Math. Anal. Appl., 461 (1): 349-353, 2018.

[3] P. A. Fillmore, J. G. Stampfli, and J. P. Williams, On the essential numerical range, the essential spectrum, and a problem of Halmos, Acta Sci. Math. (Szeged), 33: 179-192, 1972.

[4] H. Gau And P. Y. WU, Anderson's theorem for compact operators, Proc. Amer. Math. Soc., 134 (11): 3159-3162, 2006.

[5] T. Kato, Perturbation Theory for Linear Operators, Springer-Verlag, Berlin, 1995, reprint of the 1980 edition.

[6] R. Kippenhahn, Über den Wertevorrat einer Matrix, Math. Nachr., 6: 193-228, 1951.

[7] J. S. Lancaster, The boundary of the numerical range, Proc. Amer. Math. Soc., 49: 393-398, 1975.

[8] B. LINS AND I. M. SPITKOVSKY, Inverse continuity of the numerical range map for Hilbert space operators, Oper. Matrices, 14 (6): 77-90, 2020.

[9] M. NAIMI AND M. BenhaRRAT, Anderson's theorem for some class of operators, Khayyam Journal of Mathematics, 6 (2): 236-242, 2020.

[10] F. J. NARCOWICH, Analytic properties of the boundary of the numerical range, Indiana Univ. Math. J., 29 (1): 67-77, 1980.

[11] M. ReEd AND B. Simon, Methods of modern mathematical physics, I, Academic Press Inc. [Harcourt Brace Jovanovich Publishers], New York, second edition, 1980, Functional analysis.

[12] F. RelLich, Störungstheorie der spektralzerlegung, Mathematische Annalen, 113 (1): 600-619, Dec 1937.

[13] F. Riesz AND B. S. NAGY, Functional Analysis, Dover Books on Mathematics, Dover Publications, 2012.

[14] J. G. Stampfli And J. P. Williams, Growth conditions and the numerical range in a Banach algebra, Tôhoku Math. J. (2), 20: 417-424, 1968.

[15] Q. F. Stout, The numerical range of a weighted shift, Proc. Amer. Math. Soc., 88 (3): 495-502, 1983.

[16] B. SZ.-NAGY, Perturbations des transformations autoadjointes dans l'espace de Hilbert, Comment. Math. Helv., 19: 347-366, 1946. 